\title{
Natural history and growth kinetics of clear cell renal cell carcinoma in sporadic and von Hippel-Lindau disease
}

\author{
Ziao Li $^{1,2,3}$, Jin Zhang ${ }^{4}$, Lei Zhang ${ }^{1,2,3}$, Lin Yao ${ }^{1,2,3}$, Cuijian Zhang ${ }^{1,2,3}$, Zhisong He ${ }^{1,2,3}$, Xuesong Li ${ }^{1,2,3}$, \\ Liqun Zhou ${ }^{1,2,3}$ \\ ${ }^{1}$ Department of Urology, Peking University First Hospital, Beijing, China; Institute of Urology, Peking University, Beijing, China; ${ }^{2}$ National \\ Urological Cancer Center, Beijing, China; ${ }^{3}$ Beijing Key Laboratory of Urogenital Diseases (Male) Molecular Diagnosis and Treatment Center, \\ Beijing, China; ${ }^{4}$ Department of Urology, Renji Hospital, Shanghai Jiao Tong University, School of Medicine, Shanghai, China \\ Contributions: (I) Conception and design: X Li, L Zhou, J Zhang; (II) Administrative support: L Yao, L Zhou, X Li; (III) Provision of study materials \\ or patients: J Zhang, L Yao, C Zhang, Z He, X Li; (IV) Collection and assembly of data: L Zhang, Z Li; (V) Data analysis and interpretation: L \\ Zhang, Z Li; (VI) Manuscript writing: All authors; (VII) Final approval of manuscript: All authors. \\ Correspondence to: Lei Zhang; Xuesong Li. Department of Urology, Peking University First Hospital, Beijing 100034, China; Institute of Urology, \\ Peking University, Beijing 100034, China. Email: z1070501@126.com; pineneedle@sina.com.
}

\begin{abstract}
Background: To evaluate and compare the natural history and growth kinetics of sporadic clear cell renal cell carcinoma (ccRCC) with those of ccRCC in von Hippel-Lindau disease (VHL).

Methods: Sixty patients in the sporadic group with 61 tumors and 15 patients in the VHL group with 30 tumors whom all underwent delayed surgery after at least 12 months of active surveillance (AS) were enrolled to conduct a retrospective cohort study. The growth rate was calculated, and the growth kinetics between the sporadic and VHL groups were compared. The patient and tumor characteristics were reviewed, and their correlation with growth rate was analyzed.

Results: The mean growth rate of sporadic ccRCC was $0.91 \mathrm{~cm} /$ year (ranging from $0-4.74 \mathrm{~cm} /$ year) and that of VHL ccRCC was $0.47 \mathrm{~cm} /$ year (ranging from $0.04-1.89 \mathrm{~cm} /$ year). The growth rate of sporadic ccRCC showed a tendency of being faster than that of VHL ccRCC but did not reach statistical significance $(\mathrm{P}=0.07)$. The factors affecting the growth rate were different between the two groups. For VHL ccRCC, the only factor that correlated with growth rate was initial tumor diameter $(\mathrm{P}<0.001)$, but for sporadic ccRCC, the only factor was pathological nuclear grade $(\mathrm{P}<0.001)$.
\end{abstract}

Conclusions: The growth rate of VHL-associated ccRCC might be slower than that of sporadic ccRCC. Furthermore, we identified a disparity in growth kinetics between sporadic and VHL-associated ccRCC.

Keywords: Natural history; clear cell renal cell carcinoma (ccRCC); von Hippel-Lindau disease (VHL)

Submitted Sep 15, 2020. Accepted for publication Jan 05, 2021.

doi: $10.21037 /$ tau-20-1271

View this article at: http://dx.doi.org/10.21037/tau-20-1271

\section{Introduction}

With the advancement of modern medical imaging modalities, small renal masses (SRMs, defined as solid tumors less than $4 \mathrm{~cm}$ in maximum diameter) are more likely to be detected incidentally (1). Approximately $15-20 \%$ of SRMs are benign, and $20-25 \%$ are considered only potentially biologically aggressive $(2,3)$. Given the histological uncertainty of SRMs, active surveillance (AS) with delayed intervention has been widely practiced in strictly selected patients who are reluctant to undergo surgical intervention or for whom the risks of surgery are considered to outweigh the benefits (4-6). AS offers urologists a unique opportunity to study the natural history of renal cell carcinoma (RCC), as the gold standard treatment of localized kidney cancer is surgical excision at the time of diagnosis (6). Several studies have 
investigated the growth kinetics of sporadic clear cell renal cell carcinoma (ccRCC) (7-11) and ccRCC in von HippelLindau (VHL) disease (12-15); however, the difference in growth kinetics between the two groups is not well understood. Hence, the aim of our study was to further evaluate and compare the growth kinetics of sporadic ccRCC with those of ccRCC in VHL disease.

We present the following article in accordance with the STROBE reporting checklist (available at http://dx.doi. org/10.21037/tau-20-1271).

\section{Methods}

A retrospective cohort study design was used. For the sporadic group, we retrospectively reviewed the kidney cancer databases at the Institute of Urology, Peking University to identify patients who were treated with initial AS for at least 12 months between January 1990 and August 2014. A total of 90 patients with 91 renal masses were included. Patients who did not undergo delayed surgery were excluded, and only patients with ccRCC confirmed by postoperative pathology were included. Sixty patients with 61 tumors were enrolled in the sporadic group.

For the VHL group, we retrospectively reviewed the charts of 38 patients with VHL disease and enhanced renal masses between January 1988 and June 2011 who underwent AS at the Department of Urology, Renji Hospital. All patients met the clinical diagnostic criteria (16) or had a confirmed VHL gene germline mutation. Patients who did not undergo delayed surgery were excluded, and only patients with ccRCC confirmed by postoperative pathology were included. Fifteen patients with 30 tumors were enrolled in the VHL group.

During the time of AS, enhanced computed tomography (CT) was performed at least every 6 months for all patients in both groups. All images were reviewed by an experienced radiologist and a urologic oncologist. The tumor size was defined as the maximum axial diameter of the tumor on CT or MRI images. The growth rate was defined as the mean growth rate of the largest diameter.

The decision to proceed with delayed surgery was a consensus between the attending surgeon and the patient based on tumor size, growth rate, and patient factors, including general condition, surgical comorbidities, and the patient's willingness to undergo surgery. All patients in the sporadic group underwent surgery at the Peking University First Hospital, and all patients in the VHL group underwent surgery at the Renji Hospital. All surgical specimens were examined at two centers separately with the same typing and staging systems. The histological classification was determined by the Heidelberg typing system, the pathological stage was assessed according to the 2002 American Joint Committee on Cancer TNM staging system, and pathological nuclear grading was performed according to the Fuhrman grading system.

The study was conducted in accordance with the Declaration of Helsinki (as revised in 2013). The study was approved by the institutional ethical committee of Peking University First Hospital $\{2015$ [977] $\}$ and individual consent for this retrospective analysis was waived.

\section{Statistical analysis}

Wilcoxon rank-sum test and Fisher's exact test were used to compare the patient and tumor characteristics between groups. The growth rate was compared using Wilcoxon rank-sum test. Multiple linear regression was used to identify the factors that correlated with the growth rate. All statistical analyses were processed by SAS OnDemand for Academics (SAS Institute, Cary NC, USA). A $\mathrm{P}<0.05$ was considered statistically significant.

\section{Results}

Figure 1 is a flow diagram of patient selection. A total of 60 patients with $61 \mathrm{ccRCCs}$ were enrolled in the sporadic group, while 15 patients with $30 \mathrm{ccRCCs}$ were included in the VHL group. The demographic and tumor characteristics of both groups are summarized in Table 1 . The mean age of the sporadic group was 55 years (range 26-81), and that of the VHL group was 41 years (range $30-55)$.

The mean duration of AS in the sporadic group was 39.1 months, and that in the VHL group was 45.5 months $(\mathrm{P}=0.003)$. During AS, the mean tumor diameter increased from $2.36 \mathrm{~cm}$ (range $0.10-6.70 \mathrm{~cm}$ ) to $4.46 \mathrm{~cm}$ (range 1.40$11.8 \mathrm{~cm}$ ) in the sporadic group and from $2.71 \mathrm{~cm}$ (range $0.80-12.0 \mathrm{~cm}$ ) to $4.36 \mathrm{~cm}$ (range $1.5-15.0 \mathrm{~cm}$ ) in the VHL group. However, neither the mean initial tumor size nor the mean final tumor size was significantly different between the two groups. Moreover, no differences in the distribution of tumor nuclear grade and pathological $\mathrm{T}$ stage were found.

The growth rate information is detailed in Table 2, and the distributions of the linear growth rate from both groups were illustrated in Figures 2,3. The mean growth 


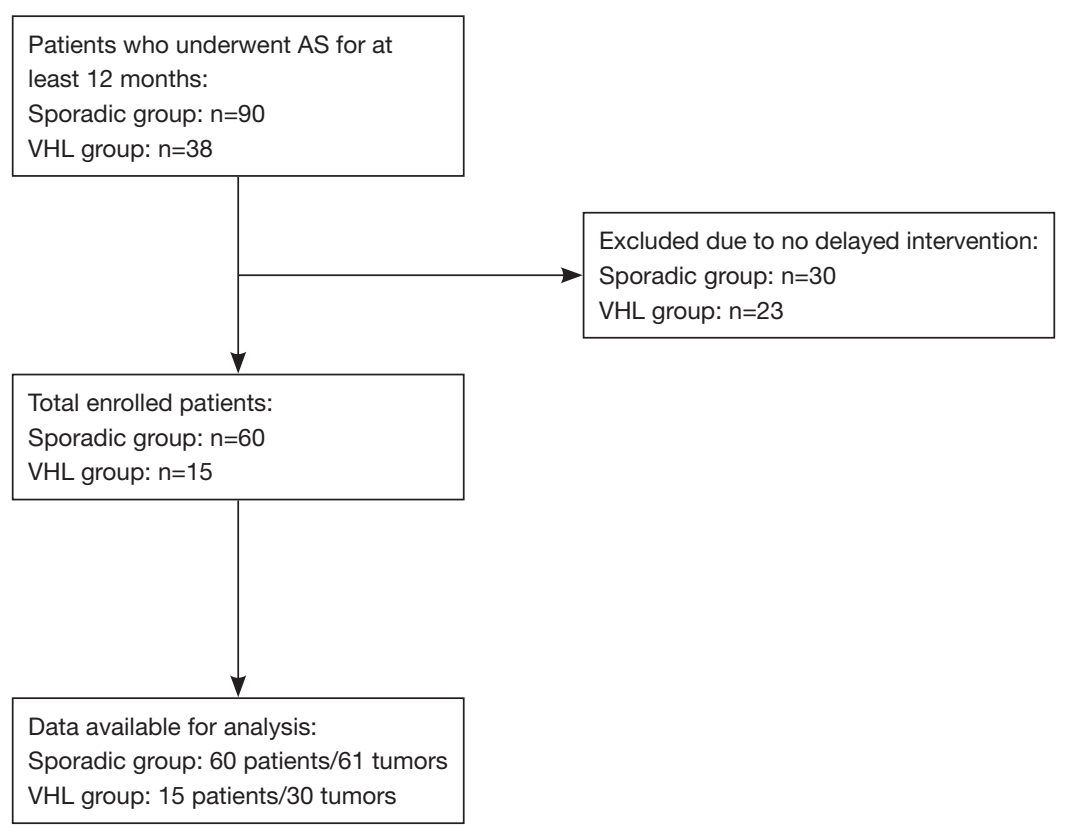

Figure 1 A flow diagram of patient selection. AS, active surveillance; VHL, von Hippel-Lindau disease.

rate of the sporadic ccRCCs was $0.91 \mathrm{~cm} /$ year (range 0.00 $4.74 \mathrm{~cm} /$ year) and that of VHL ccRCCs was $0.47 \mathrm{~cm} /$ year (range $0.04-1.89 \mathrm{~cm} /$ year). The growth rate of sporadic ccRCC showed a tendency of being faster than that of VHL ccRCC but did not reach statistical significance $(\mathrm{P}=0.07)$.

We further analyzed the factors that correlated with the growth rate in the two groups (Table 2). In the sporadic group, only the pathological nuclear grade was strongly correlated with growth rate $(\mathrm{P}<0.001)$, while in the VHL group, the only factor related to the growth rate was initial tumor size $(\mathrm{P}<0.001)$. Age and sex did not correlate with growth rate in either group.

\section{Discussion}

ccRCC is the most common malignancy of the kidney. The only curative treatment supported by high-quality evidence is surgery (6), so the patient and surgeon often pursue prompt intervention soon after the diagnosis. Hence, investigating the in vivo growth rate of ccRCC has been difficult. AS provides urologists a unique way to study the growth pattern and kinetics of ccRCC. Previous studies suggested that ccRCCs in VHL disease may be more indolent than sporadic ccRCCs (12-15), and our study showed a similar tendency. However, due to the limited sample size, we need further study to confirm this phenomenon.

Given the fact that predictors of rapid tumor growth rate remain elusive (7), we further investigated the factors related to the growth rate. A study conducted by Kouba et al. reported a faster growth rate in young patients than in old patients (17); however, our previous study (11) and this study failed to identify a correlation between age and growth rate in either group.

Several studies have demonstrated that there is no significant correlation between initial tumor diameter and growth rate in both sporadic and VHL-associated ccRCC (4,10,17-22). Interestingly, our study demonstrated that the initial tumor diameter was the only factor that was significantly related to the growth rate in the VHL group, but this factor did not correlate with the growth rate in the sporadic group.

Regarding the relationship between nuclear grade to growth rate, previous studies reported different conclusions. Oda $e t$ al. could not establish a relationship between growth rate and nuclear grade in sporadic ccRCCs (23), but Kato et al. found that Fuhrman grade III tumors had a faster growth rate than Fuhrman grade I-II tumors (24). Our study showed a strong relationship between nuclear grade and growth rate in the sporadic group but failed to identify this relationship in the VHL group.

We hypothesize that the intratumoral heterogeneity of 
Table 1 Patient demographics and tumor characteristics

\begin{tabular}{|c|c|c|c|}
\hline & $\begin{array}{c}\text { ccRCCs in sporadic } \\
\text { disease, } n=61\end{array}$ & $\begin{array}{l}\text { ccRCCs in } \\
\text { VHL, } n=30\end{array}$ & $P$ value \\
\hline Number of patients & 60 & 15 & 0.363 \\
\hline Men (\%) & 47 (78.3) & $7(46.7)$ & \\
\hline Women (\%) & $13(21.7)$ & 8 (53.3) & \\
\hline Age, yr & & & $<0.001$ \\
\hline Median & 56 & 42 & \\
\hline Mean & 55 & 41 & \\
\hline Range & $26-81$ & $30-55$ & \\
\hline \multicolumn{2}{|c|}{ Initial tumor diameter, cm } & & 0.333 \\
\hline Median & 1.90 & 2.40 & \\
\hline Mean & 2.36 & 2.71 & \\
\hline Range & $0.10-6.70$ & $0.80-12.0$ & \\
\hline \multicolumn{2}{|c|}{ Final tumor diameter, cm } & & 0.813 \\
\hline Median & 4.00 & 3.75 & \\
\hline Mean & 4.46 & 4.36 & \\
\hline Range & $1.40-11.8$ & $1.5-15.0$ & \\
\hline \multicolumn{2}{|c|}{ Duration of AS, months } & & 0.003 \\
\hline Median & 27.00 & 48 & \\
\hline Mean & 39.1 & 45.5 & \\
\hline Range & $2-155$ & $19-85$ & \\
\hline Grade & & & 0.419 \\
\hline $1(\%)$ & $14(23.0)$ & $6(20.0)$ & \\
\hline $2(\%)$ & $36(59.0)$ & $23(76.7)$ & \\
\hline $3(\%)$ & $11(18.0)$ & $1(3.3)$ & \\
\hline Pathological stage & & & 0.215 \\
\hline T1a (\%) & $30(49.2)$ & $18(60.0)$ & \\
\hline T1b (\%) & $21(34.4)$ & $10(33.3)$ & \\
\hline T2 (\%) & $5(8.2)$ & $2(6.7)$ & \\
\hline T3 (\%) & $5(8.2)$ & $0(0)$ & \\
\hline
\end{tabular}

VHL, von Hippel-Lindau disease; AS, active surveillance.

sporadic ccRCC is the cause of this disparity. Before further discussion, it is imperative for us to mention that although the heterogeneity of sporadic ccRCC is well established (25-28), we could not find clear evidence to prove that VHL-associated ccRCC is genetically less heterogeneous than the sporadic. However, by assuming a less
Table 2 Growth rate for ccRCCs: overall and correlation with clinicopathologic variables

\begin{tabular}{lcc}
\hline & $\begin{array}{c}\text { Growth rate of sporadic } \\
\text { ccRCCs, } \mathrm{n}=61(\mathrm{~cm} / \text { year })\end{array}$ & $\begin{array}{c}\text { Growth rate of ccRCCs } \\
\text { in VHL, } \mathrm{n}=30(\mathrm{~cm} / \text { year })\end{array}$ \\
\hline $\begin{array}{l}\text { Growth rate } \\
\text { Median }\end{array}$ & 0.61 & 0.43 \\
Range & $0.00-4.74$ & $0.04-1.89$ \\
Mean \pm SD & $0.91 \pm 1.03$ & $0.47 \pm 0.31$ \\
P value & & 0.07
\end{tabular}

Growth rates and clinicopathologic variables

Pathological Grade

$\begin{array}{lcc}\text { Grade 1 } & 0.35 \pm 0.22(n=14) & 0.35 \pm 0.06(n=6) \\ \text { Grade } 2 & 0.74 \pm 0.68(n=36) & 0.50 \pm 0.35(n=23) \\ \text { Grade 3 } & 2.17 \pm 1.56(n=11) & 0.54(n=1) \\ \text { P value } & <0.001 & 0.316 \\ \text { Initial size } & & 0.627 \\ R^{2} & 0.016 & <0.001 \\ \text { P value } & 0.325 & 0.076 \\ \text { Age } & & 0.142 \\ R^{2} & 0.0005 & \\ P \text { value } & 0.862 & 0.40 \pm 0.14 \\ \text { Sex } & & 0.63 \pm 0.51 \\ \text { Men } & 0.88 \pm 1.05 & 0.197 \\ \text { Women } & 1.00 \pm 1.02 & \\ P \text { value } & 0.383 & \text { von Hippel-Lindau } \\ \text { CRCC, clear cell renal cell carcinoma; VHL, von } & & \\ \text { isease. } & & \end{array}$

heterogeneity in VHL-associated ccRCC, this disparity could be easily explained. In a highly heterogeneous tumor, e.g., the sporadic ccRCC, we postulate that the most aggressive part of the tumor contributes the most to the growth rate, thus resulting in different growth potential among tumors with similar size. While in a less heterogeneous tumor, e.g., the VHL-associated ccRCC, the main factor that would affect the growth rate would be the size of the tumor.

Regarding the failure of identifying a unifying predictor of rapid tumor growth from previous studies, we believe this could be partially attributed to the intertumoral heterogeneity in ccRCC, which is a less established 


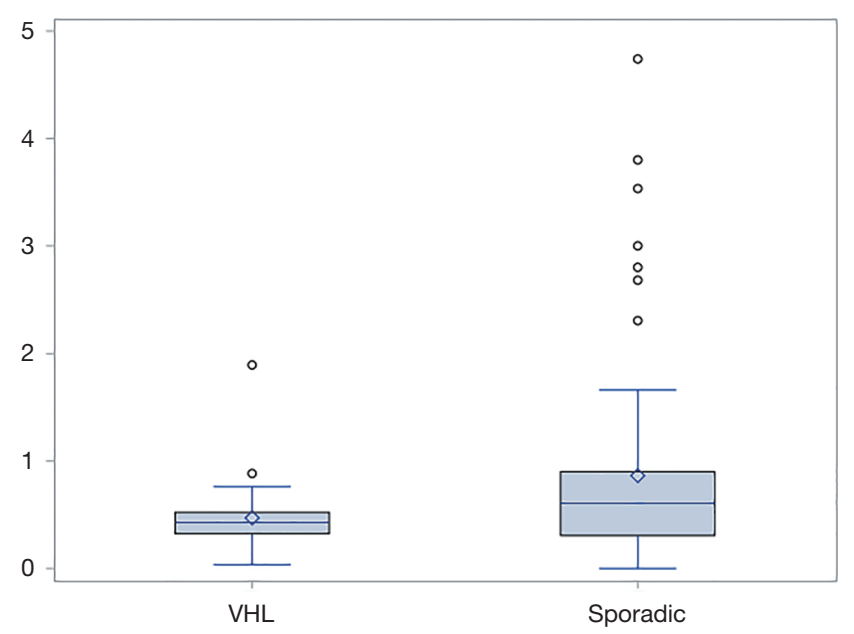

Figure 2 A box plot of mean LGR for both groups. LGR, linear growth rate; VHL, von Hippel-Lindau disease. phenomenon than intratumoral heterogeneity (28). In Figures 2,3, our data demonstrated that the growth rate of sporadic ccRCC is highly variated, supporting the existence of intertumoral heterogeneity, hence warranting a consideration of this less reported heterogeneity for future studies. However, this hypothesis requires extensive further investigations before a fully concrete conclusion can be made. Moreover, our study has inherent limitations due to the retrospective nature of this study, intra- and interobserver variability, selection bias, and inclusion of a rather small sample size.

\section{Conclusions}

We showed that the growth rate of VHL-associated ccRCC might be slower than that of sporadic ccRCC. Furthermore,

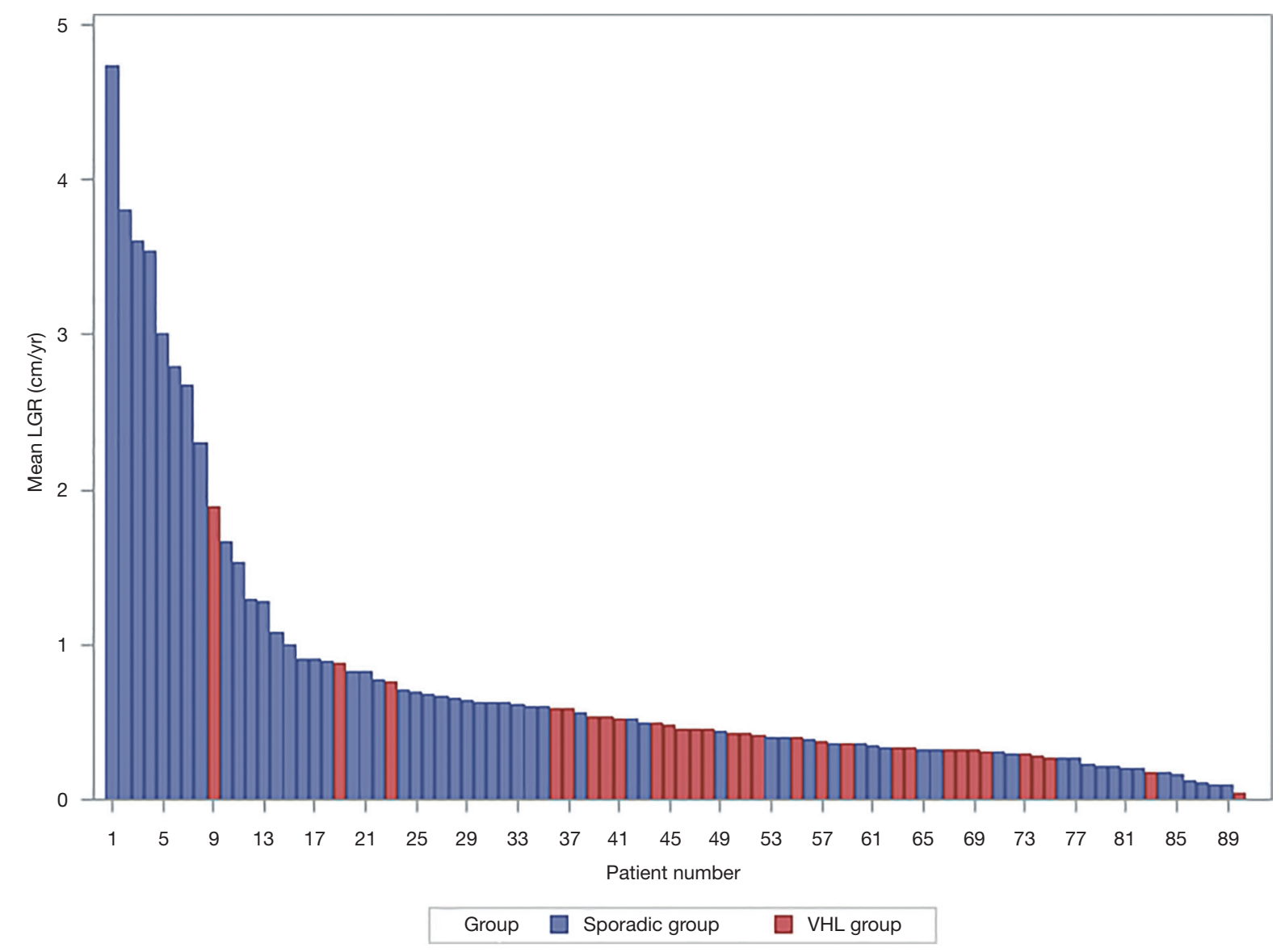

Figure 3 A waterfall plot of mean LGR for all tumors. LGR, linear growth rate; VHL, von Hippel-Lindau disease. 
we identified a disparity in growth kinetics between sporadic and VHL-associated ccRCC. The only factor that correlated with growth rate was initial tumor diameter in VHL-associated ccRCC and in contrast, nuclear grade in sporadic ccRCC. Extensive investigations are required to further validate and elucidate this correlation.

\section{Acknowledgments}

Funding: This work was supported by Research Foundation of Peking University First Hospital (grant number 2018SF064).

\section{Footnote}

Reporting Checklist: The authors have completed the STROBE reporting checklist. Available at http://dx.doi. org/10.21037/tau-20-1271

Data Sharing Statement: available at http://dx.doi. org/10.21037/tau-20-1271

Conflicts of Interest: All authors have completed the ICMJE uniform disclosure form (available at http://dx.doi. org/10.21037/tau-20-1271). Xuesong Li serves as an unpaid editorial board member of Translational Andrology and Urology. Li-Qun Zhou serves as an unpaid editorial board member of Translational Andrology and Urology from Mar 2020 to Feb 2022. The other authors have no conflicts of interest to declare.

Ethical Statement: The authors are accountable for all aspects of the work in ensuring that questions related to the accuracy or integrity of any part of the work are appropriately investigated and resolved. The study was conducted in accordance with the Declaration of Helsinki (as revised in 2013). The study was approved by the institutional ethical committee of Peking University First Hospital (2015 [977]) and individual consent for this retrospective analysis was waived.

Open Access Statement: This is an Open Access article distributed in accordance with the Creative Commons Attribution-NonCommercial-NoDerivs 4.0 International License (CC BY-NC-ND 4.0), which permits the noncommercial replication and distribution of the article with the strict proviso that no changes or edits are made and the original work is properly cited (including links to both the formal publication through the relevant DOI and the license). See: https://creativecommons.org/licenses/by-nc-nd/4.0/.

\section{References}

1. Hollingsworth JM, Miller DC, Daignault S, et al. Rising incidence of small renal masses: a need to reassess treatment effect. J Natl Cancer Inst 2006;98:1331-4.

2. Kutikov A, Fossett LK, Ramchandani P, et al. Incidence of benign pathologic findings at partial nephrectomy for solitary renal mass presumed to be renal cell carcinoma on preoperative imaging. Urology 2006;68:737-40.

3. Rothman J, Egleston B, Wong YN, et al. Histopathological characteristics of localized renal cell carcinoma correlate with tumor size: a SEER analysis. J Urol 2009;181:29-33.

4. Chawla SN, Crispen PL, Hanlon AL, et al. The natural history of observed enhancing renal masses: meta-analysis and review of the world literature. J Urol 2006;175:425-31.

5. Heuer R, Gill IS, Guazzoni G, et al. A critical analysis of the actual role of minimally invasive surgery and active surveillance for kidney cancer. Eur Urol 2010;57:223-32.

6. Ljungberg B, Bensalah K, Canfield S, et al. EAU guidelines on renal cell carcinoma: 2014 update. Eur Urol 2015;67:913-24..

7. Ristau BT, Correa AF, Uzzo RG, et al. Active Surveillance for the Small Renal Mass: Growth Kinetics and Oncologic Outcomes. Urol Clin North Am 2017;44:213-22.

8. Jewett MA, Mattar K, Basiuk J, et al. Active surveillance of small renal masses: progression patterns of early stage kidney cancer. Eur Urol 2011;60:39-44.

9. Li XS, Yao L, Gong K, et al. Growth pattern of renal cell carcinoma (RCC) in patients with delayed surgical intervention. J Cancer Res Clin Oncol 2012;138:269-74.

10. Rosales JC, Haramis G, Moreno J, et al. Active surveillance for renal cortical neoplasms. J Urol 2010;183:1698-702.

11. Zhang L, Yin W, Yao L, et al. Growth Pattern of Clear Cell Renal Cell Carcinoma in Patients with Delayed Surgical Intervention: Fast Growth Rate Correlates with High Grade and May Result in Poor Prognosis. Biomed Res Int 2015;2015:598134.

12. Walther MM, Choyke PL, Glenn G, et al. Renal cancer in families with hereditary renal cancer: prospective analysis of a tumor size threshold for renal parenchymal sparing surgery. J Urol 1999;161:1475-9.

13. Choyke PL, Glenn GM, Walther MM, et al. The natural history of renal lesions in von Hippel-Lindau disease: a serial CT study in 28 patients. AJR Am J Roentgenol 1992;159:1229-34. 
14. Neumann HP, Bender BU, Berger DP, et al. Prevalence, morphology and biology of renal cell carcinoma in von Hippel-Lindau disease compared to sporadic renal cell carcinoma. J Urol 1998;160:1248-54.

15. Zhang J, Pan JH, Dong BJ, et al. Active surveillance of renal masses in von Hippel-Lindau disease: growth rates and clinical outcome over a median follow-up period of 56 months. Fam Cancer 2012;11:209-14.

16. Maher ER, Yates JR, Harries R, et al. Clinical features and natural history of von Hippel-Lindau disease. Q J Med 1990;77:1151-63.

17. Kouba E, Smith A, McRackan D, et al. Watchful waiting for solid renal masses: insight into the natural history and results of delayed intervention. J Urol 2007;177:466-70.

18. Steinbach F, Novick AC, Zincke H, et al. Treatment of renal cell carcinoma in von Hippel-Lindau disease: a multicenter study. J Urol 1995;153:1812-6.

19. Abouassaly R, Lane BR, Novick AC. Active surveillance of renal masses in elderly patients. J Urol 2008;180:505-8.

20. Beisland C, Hjelle KM, Reisæter LA, et al. Observation should be considered as an alternative in management of renal masses in older and comorbid patients. Eur Urol 2009;55:1419-27.

21. Abou Youssif T, Kassouf W, Steinberg J, et al. Active surveillance for selected patients with renal masses: updated results with long-term follow-up. Cancer

Cite this article as: Li Z, Zhang J, Zhang L, Yao L, Zhang C, He Z, Li X, Zhou L. Natural history and growth kinetics of clear cell renal cell carcinoma in sporadic and von Hippel-Lindau disease. Transl Androl Urol 2021;10(3):1064-1070. doi: 10.21037/ tau-20-1271
2007;110:1010-4.

22. Sowery RD, Siemens DR. Growth characteristics of renal cortical tumors in patients managed by watchful waiting. Can J Urol 2004;11:2407-10.

23. Oda T, Miyao N, Takahashi A, et al. Growth rates of primary and metastatic lesions of renal cell carcinoma. Int J Urol 2001;8:473-7.

24. Kato M, Suzuki T, Suzuki Y, et al. Natural history of small renal cell carcinoma: evaluation of growth rate, histological grade, cell proliferation and apoptosis. J Urol 2004;172:863-6.

25. Okegawa T, Morimoto M, Nishizawa S, et al. Intratumor Heterogeneity in Primary Kidney Cancer Revealed by Metabolic Profiling of Multiple Spatially Separated Samples within Tumors. EBioMedicine 2017;19:31-8.

26. Guarch R, Lawrie CH, Larrinaga G, et al. High levels of intratumor heterogeneity characterize the expression of epithelial-mesenchymal transition markers in highgrade clear cell renal cell carcinoma. Ann Diagn Pathol. 2018;34:27-30.

27. López JI, Angulo JC. Pathological Bases and Clinical Impact of Intratumor Heterogeneity in Clear Cell Renal Cell Carcinoma. Curr Urol Rep 2018;19:3.

28. Beksac AT, Paulucci DJ, Blum KA, et al. Heterogeneity in renal cell carcinoma. Urol Oncol 2017;35:507-15. 